\section{One for all}

No matter if you're a dentist, dental technician or even dental student, there will always be a place for you at the British Academy of Cosmetic Dentistry (BACD).

As a member, everyone at the BACD will be given the chance to form lasting relationships with other professionals and take every opportunity to learn from one another.

A true highlight of being a part of the BACD is how everyone works together to ensure that no one ever stops learning. Working with likeminded colleagues, there will be endless occasions to challenge and encourage each other to be the best that you can be.

As a BACD member, there's nothing you can't achieve.

For further enquiries about membership of the British Academy of Cosmetic Dentistry, visit www.bacd.com.

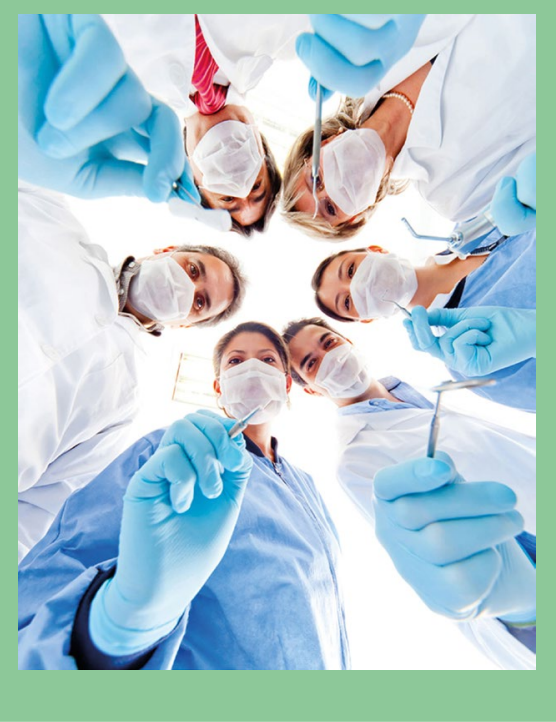

\title{
Light the way
}

Light the way in your practice with the EyeMag Light II - the perfect complement to the EyeMag Pro dental loupes available from Nuview.

The EyeMag Light II produces nearcoaxial lighting that closely resembles natural daylight, which is evenly distributed across your entire field of view to ensure minimal shadow formation. It also features a swing-in orange filter that prevents premature curing of composite materials during handling.

Complete with two powerful, rechargeable battery packs and a convenient charging cradle, the EyeMag Light II facilitates a virtually interruption-free

workflow to promote maximum productivity.

For more information call Nuview on 01453 872266, email info@nuview-ltd.com, visit www.nuview.co.uk or 'like' Nuview on Facebook

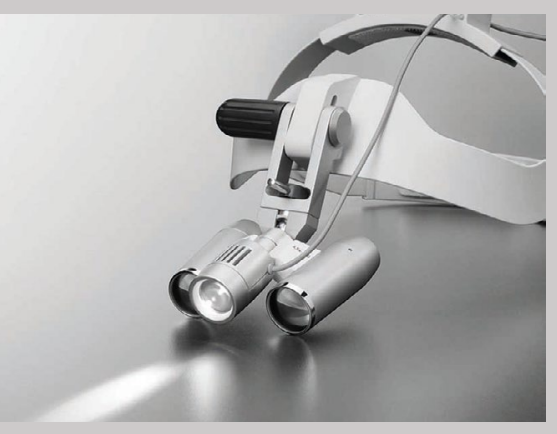

\section{Simplify your workflow}

Clark Dental strives to support dental practitioners with top-quality treatment centres manufactured by Sirona. This includes the ultra-compact Sinius unit, offering three different treatment concepts: sliding track, Traditional Style, and Continental Style.

The Sinius features a wireless foot control, a unique chair lift system, and a motorised headrest that automatically moves the patient's head into the desired position for optimal access to the oral cavity.

Available in a wide range of vibrant upholstery colours, the Sinius also enables you to simplify your workflow with ease and efficiency by providing integrated treatment packages for implantology and endodontics.

For more information call Clark Dental on 01268733 146, email info@clarkdental. co.uk or visit www.clarkdental.co.uk.

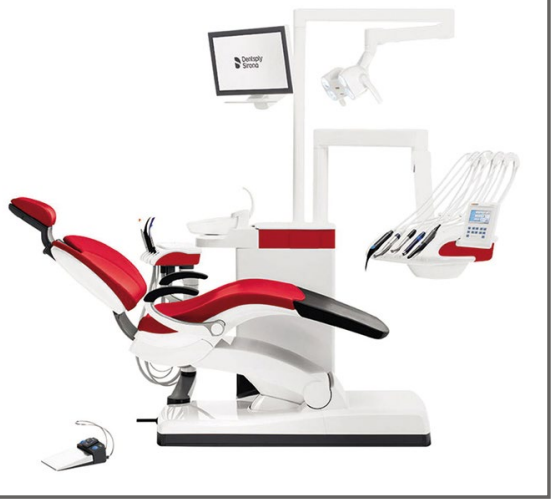

\section{No more guesswork}

When the $\mathrm{x}$-ray film is inside the mouth it's difficult to know exactly where it is, especially when patients inadvertently move it with their tongue as they swallow. Dürr Dental's film holders remove the guesswork, so that the radiation hits the correct tooth, at the correct angle, hitting $100 \%$ of the film. No more retakes!

Moreover, these holders have been developed specifically for use with phosphor plates, so they won't cause damage, unlike traditional ones designed for use with film.
To facilitate use, the holders have been colour-coded, which saves time when assembling. They are also available to buy as individual components, so that if an element gets lost, or eventually becomes worn, then only that component needs to be ordered. This saves money and has environment benefits too.

Dürr's image plate holders can be used with any make of phosphor plate and will allow you to position the film exactly where you want it. They won't distort over time and offer the patient significantly improved radiation protection.

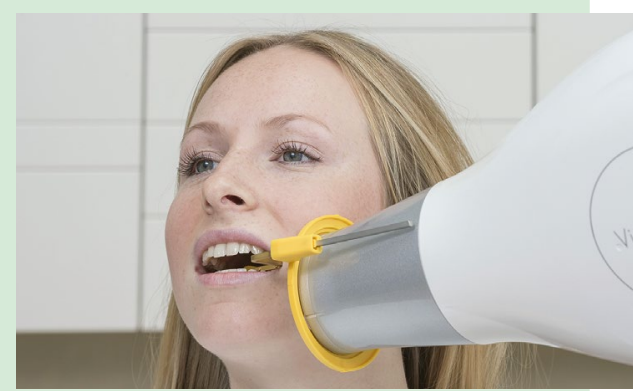

